Arndt Hampe

\title{
Fecundity limits in Frangula alnus (Rhamnaceae) relict populations at the species' southern range margin
}

\begin{abstract}
The geographic range of many temperate plant species is constrained by climate, but it remains little known how climate affects population performance at low-latitude range margins. This study investigated the reproduction of the Eurasian tree Frangula alnus in relict populations near its southwestern range limit in southern Spain. The aim was to identify the principal stages and causes of ovule loss experienced by these marginal populations. More than 6,800 flowers were monitored over 2 years, insect observations and different experiments were carried out to assess levels of pollen and resource limitation, as well as the influence of flowering phenology on seed production. Most ovule losses occurred during flower anthesis and were due to strong cross-pollen limitation. Fruit set was affected by tree size, light regime and flowering phenology, probably through their effects on pollinator behaviour. Fruit set was almost zero throughout the first half of the flowering season. Then it increased paralleling changes in pollinator abundance but was soon overridden by increasing ovule desiccation due to summer drought. Successful seed production was mostly confined to a brief period near the end of the flowering season. Adverse weather during this period in the second study year resulted in a threefold bud and flower mortality and a $50 \%$ decrease of fruit production. Spring rainfalls in southwestern Spain have diminished more than 30\%
\end{abstract}

Electronic Supplementary Material Supplementary material is available in the online version of this article at http://dx.doi.org/ 10.1007/s00442-004-1811-0

\footnotetext{
A. Hampe

Departamento de Biologia Vegetal y Ecologia,

Universidad de Sevilla, PO Box 1095,

41080 Sevilla, Spain

Present address: A. Hampe

Integrative Ecology Group,

Estacion Biologica de Donana (CSIC),

PO Box 1056, 41080 Sevilla, Spain

E-mail: arndt@ebd.csic.es

Tel.: +34-954-232340

Fax: +34-954-621125
}

through past decades leading to an earlier onset of summer drought. This trend and its adverse effects on seed production may contribute to explaining the recent decline of F. alnus at its southwestern range limit.

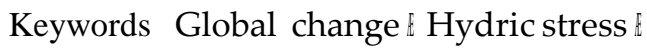

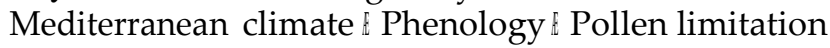

\section{Introduction}

The geographic range of many temperate plant species is determined by climate (Woodward 1987). Presumably, populations from the centre of the range experience the most favourable environmental conditions, while environmental suitability decreases with distance from the distribution centre and populations become smaller and more prone to extinction towards the periphery of the species range (Lawton 1993). Both reproduction and establishment are usually the life cycle stages most susceptible to adverse environmental conditions and they commonly determine the environmental tolerance of populations (Woodward 1987; Pigott 1992). Numerous studies have examined the reproductive biology of peripheral plant populations to identify factors and processes that limit their regeneration and viability (e.g. Pigott and Huntley 1981; Houle and Filion 1993; Despland and Houle 1997; Wagner and Mitterhofer 1998; Dorken and Eckert 2001; Tremblay et al. 2002). However, by far most of this research has been carried out in populations from high-latitude or altitude limits of the range, while populations at the opposite range margins have received little attention (but see Garcia et al. 1999; Hampe and Bairlein 2000; Castro et al. 2004; Hampe 2004).

Populations near low-latitude range margins are confronted with environmental constraints quite different from those at the other extreme of the species' distribution. Not low temperatures but water availability is usually the principal limiting climatic factor for 
populations at low-latitude edges (Pigott and Pigott 1993; Garcia et al. 1999; Castro et al. 2004). Accordingly, summer is the most problematic season and the most unfavourable and stressful climatic conditions often interfere with the reproduction process, even though growth and reproduction usually begin earlier than at higher latitudes (Rotzer and Chmielewski 2001). Populations at lower latitudes or altitudes tend to interact more intensely with invertebrates, for instance pollinators and herbivores (Kevan and Baker 1983; Bale et al. 2002; Olesen and Jordano 2002). Hence, pollen limitation may be less important, whereas invertebrate herbivory may have a higher impact than in other parts of the range.

At low-latitude range margins, populations of temperate species are most often restricted to isolated, particular humid and cool habitats that mitigate adverse effects of the regional climate. Their conservation is becoming increasingly difficult, because the extent and impact of summer drought have been increasing in many regions throughout the last decades and further increases have been anticipated (IPCC 2001). Modern climate change aggravates environmental constraints for plant and animal relict populations persisting at lowlatitude range margins, and recent poleward range shifts have become manifest across many taxa (Parmesan and Yohe 2003). It remains, however, little investigated if the reproductive potential of low-latitude marginal populations is primarily limited by resources, in particular water availability, or by biotic factors, such as pollination or herbivory: in other words, if direct or indirect effects of climate change prevail in driving the ongoing erosion of low-latitude range margins. A better identification and understanding of the multiple constraints on reproduction and regeneration of relict populations is therefore crucial for the design of appropriate conservation strategies (Bond 1995; Castro et al. 2004).

The present study examines the reproductive biology of the Eurasian tree Frangula alnus Miller (Rhamnaceae) in relict populations from the southwestern extreme of its distribution range in southern Spain. Specifically, it aims to (1) quantify individual fecundity and seed production in two consecutive years, (2) identify the principal stages and factors of ovule loss, (3) assess the role of flowering phenology on seed set, and (4) evaluate implications for conservation of the relict populations in a changing environment.

\section{Materials and methods}

\section{Study organism}

Frangula alnus Miller (Rhamnaceae) is a deciduous shrub or small tree that grows in most of temperate Europe and western Asia (Hampe et al. 2003). In the southwestern extreme of its range, the subspecies F. alnus baetica (Rev. and Willk.) Rivas Goday ex Devesa is sparsely distributed across mountain ranges and some wetlands of southern Spain and North Morocco. It is in decline and considered vulnerable according to IUCN standards by the Spanish National Red List (Anonymous 2000).

Trees of the subspecies baetica become up to $15 \mathrm{~m}$ tall and 60 years old, and grow typically in the understorey of $10-20 \mathrm{~m}$ broad, a few hundred metres to a few kilometres long riparian forests along small, shady creeks surrounded by mediterranean sclerophyllous and semideciduous forests (Hampe and Arroyo 2002; Hampe 2004). The reproductive biology of $F$. alnus has been described in detail by Godwin (1943), Medan (1994) and Hampe and Bairlein (2000). The species is self-incompatible. Its small hermaphroditic, protandrous flowers are arranged in axillary inflorescences along the currentyear shoots (see Fig. S1 in the Electronic Supplementary Material, Appendix) and are produced from April until growing ceases due to summer drought. Fruits are black berries with two or three one-seeded stones, that ripen from end June until mid August or September and are consumed by a variety of resident birds (Hampe 2001). According to Medan (1994), the species' seed output is very low (1.5\% of initiated ovules), while Hampe and Arroyo (2002) report that the seed production of populations relies largely on a small fraction of old trees and state that it may be reduced in small populations due to inbreeding depression.

\section{Study area}

The study was carried out in two populations (Puerto Oscuro and Medio) located in gorges of the Aljibe Mountain Range about $40 \mathrm{~km}$ NNW of Gibraltar $\left(36^{\circ} 30 \mathrm{cN} 5^{\circ} 35 \mathrm{cW}\right.$; Cadiz province, Spain). Mean temperature of the area is about $16.7^{\circ} \mathrm{C}$; annual rainfall averages $880 \mathrm{~mm} /$ year (SinambA Difusion 1998). However, the water supply within the gorges is considerably higher and more constant due to additional humidity delivered by low clouds and fog (J. Arroyo, unpublished data). The study sites are $5 \mathrm{~km}$ apart from each other and separated by a major water shed. Their riparian forests are little altered by man, and F. alnus ssp. baetica is common in the dense woody vegetation dominated by Alnus glutinosa (L.) Gaertn., Rhododendron ponticum subsp. baeticum (Boiss. and Reuter) Hand.-Mazz., Arbutus unedo L., Viburnum tinus L. and Quercus canariensis Willd. The Puerto Oscuro Gorge holds one of the largest known populations of the subspecies with $>1,000$ adult plants, while the Medio population contains around 500 adults and large saplings.

\section{Shoot monitoring}

Prior to the 2000 flowering season I marked five haphazardly chosen, current-year branches on each of 33 trees (20 in the Puerto Oscuro and 13 in the Medio 
population) and monitored them every 6-7 days until the end of the fruiting season. Selection of trees was partly determined by their accessability, and flowering shoots were usually checked using a ladder or from nearby rocks. During each census I recorded the current stage (bud, open flower, wilted flower, unripe fruit, ripe fruit) of all flowers in each inflorescence. Visible flower or fruit damages, as well as putative factors of flower and fruit mortality were likewise recorded: (1) herbivory, (2) desiccation, (3) intrinsic factors (when buds or fruits stopped growing and/or changed their colour before falling off) or (4) unknown (when buds or fruits disappeared between censuses without leaving any signs of the mortality factor). The monitoring procedure was repeated in 2001 on a subset of 15 trees (7 in the Medio population and 8 in the Puerto Oscuro population) until the start of the fruiting period. Then branches were carefully protected with a fine mesh to prevent the removal of fruits, and these were sampled just after ripening and carried to the laboratory to determine their fresh mass, total seed number and number of filled seeds, individual and total seed mass, as well as the ratio between total seed mass and fruit fresh mass.

\section{Pollinator observations}

Four trees were monitored in each population in 2000 and 2001 to describe pollinator communities and behaviour. Visitation rates were examined by permanently marking one branch per tree and monitoring it weekly during $15 \mathrm{~min}$. It was not possible to follow all insects individually and determine the actual number of flowers visited, so each pollinator that approached at least one flower before leaving the branch was counted as one visit. After each observation period all open flowers of the monitored branch were counted and checked for the presence of previously undetected insects (mostly Coleoptera; Thysanoptera were abundant but could not be quantified and were not considered).

\section{Pollen addition}

In early June 2003 I conducted a pollen addition experiment to check if plants were pollen-limited even at the moment of highest pollinator availability per flower (as observed in 2000 and 2001). For this purpose, I selected five trees in each population and marked ten inflorescences on each tree that contained two flowers in the female phase of flowering, respectively. One flower was pollinated by gently touching the stigma with anthers from two distant trees, while the other flower was left as a control. Flower assignment followed a randomization procedure. The initial fruit set was examined 1 week later. Developing fruits were protected from removal as described above and collected after ripening for morphometric analyses.
Leaf removal

Patterns of resource limitation on fruit production are usually assessed by removing plant tissues that are assumed to influence fruit production. Although resource translocation may be extensive in trees such as F. alnus and render interpretations of experimental results difficult, the species' particular morphology with its axillary inflorescences (see Fig. S1, Electronic Supplementary Material) suggests that resource levels of inflorescences are probably influenced by the supporting leaf. Levels of both carbohydrates and water may be affected, through the neighbouring leaf's photosynthesis as well as its transpiration and resulting maintenance of a negative water potential. A leaf removal experiment was therefore carried out to assess potential impacts of local carbohydrate and/or water restriction on fruit production. Prior to the flowering period 2001 five triplets of similar shoots were marked on each of five trees of the Medio population, and each shoot within its triplet was randomly assigned to one of the following treatments: (1) all leaves removed, (2) every second leaf removed, and (3) no leaf removed. All shoots were monitored weekly and flowering, fruiting and fruit characterictics were recorded as described above. All leaves appearing after the initial treatment were clipped according to the experimental scheme. The removal of entire leaves corresponded to the behaviour of the most important leaf herbivores in the area, caterpillars of Gonepteryx cleopatra and G. rhamni (Lepidoptera), which tend to consume leaves more or less completely. Although a few trees were heavily infested, population-level damages were limited. Further damage caused by leaf-cutting bees was likewise rather minor both at the individual and the population level (A. Hampe, unpublished data).

\section{Manipulation of flowering phenology}

This experiment was designed to examine if fruit initiation and development vary according to the timing of flowering. In early April 2001 three sets of four similar shoots were marked, respectively, on nine trees in the Puerto Oscuro population. Shoots were checked every 2-3 days and recently opened flowers were carefully clipped with scissors according to the treatment: (1) early flowering (latest $50 \%$ of the flowers clipped), (2) late flowering (earliest $50 \%$ clipped), (3) peak flowering (earliest and latest 25\% clipped), and (4) control (every second flower clipped). After the end of the manipulation period fruits were monitored weekly and ripe fruits were collected and analysed.

\section{Tree-related data}

Several parameters were recorded to characterize the 33 trees monitored in 2000. The numbers of flowers on 
50 haphazardly chosen shoots were counted at the beginning of the flowering period (partly using binoculars) and multiplied by the total number of flowerbearing shoots to obtain the total number of flowers on each tree. All conspecific flowering trees within a $10-\mathrm{m}$ radius around each focal tree were counted. Finally, a hemispherical photograph was taken at each focal tree soon after the end of the flowering period, whereby the camera was adjusted above the highest of the five monitored shoots.

\section{Statistical analyses}

For each monitored shoot I calculated initial fruit set (i.e., the fraction of flowers initiating a fruit) and final fruit set (the fraction of flowers developing into a mature fruit). All statistical comparisons between the two study years considered only the 15 trees monitored over both years. Nested analyses of variance (ANOVA) were used for analysing flowering patterns and results of the experiments. Generalized linear models (GLM) with Poisson or binomial errors were used instead of leastsquares ANOVA when data could not be normalized. All models included tree identity as a factor to account for intrinsic differences between individuals, while residual variation between trees was specified as error term. A key-stage analysis (Yamamura 1999) was carried out to quantify ovule mortality through the different stages of the reproductive process and its variation between 2000 and 2001.

Density-dependence of initial and final fruit set was assessed using weighted linear regression on log-transformed values. This approach is superior to simple linear regression (commonly used to test for density-dependence), because it precludes regression slopes being biased when extreme values are represented by small sample sizes (Crawley 2002). Analyses were conducted separately for the 2000 and the 2001 observational data using GLM with binomial errors. Density-dependence of fruit initiation was assessed considering flower number (log transformed) as an independent and initiated fruit number (logit transformed) per inflorescence as a dependent variable, whereas analyses of fruit development included the numbers of initiated (log transformed) and ripe fruits (logit transformed) per infructescence. Tree identity was included as an additional factor, resulting in a weighted ANCOVA design. The difference of resulting covariate slopes from 1 was assessed with $\mathrm{v}^{2}$ tests as recommended by Crawley (2002).

Finally, a multiple linear regression was carried out on the 33 trees monitored in 2000 to examine how their initial and final fruit set were influenced by tree characteristics and the environment. The following were considered as independent variables: number of flowers on the tree, mean inflorescence number per shoot, mean inflorescence size, mean flowering date, number of flowering conspecifics within a $10-\mathrm{m}$ radius, as well as the two light measures direct site factor (DSF) and indirect site factor (ISF). DSF and ISF express the proportion of direct and diffuse solar radiation that reaches a given point, relative to a location with no sky obstructions. They were calculated from the hemispherical photographs using the software HemiView 2.1 (Delta-T Devices 1998). The tolerance of the independent variable set was 0.15 , which suggests a comparatively low level of redundancy (Philippi 1993). Analyses were done using the $\mathrm{R}$ software version 2.0.0 ( $\mathrm{R}$ Development Core Team 2004) or Statistica version 6.0 (StatSoft 2001). Means \pm 1 SD are given throughout the paper if not stated otherwise.

\section{Results}

Spatial and temporal patterns of flowering, fruit set and mortality

A total of 1,006 inflorescences containing 4,446 flowers were monitored in 2000 and 481 inflorescences with 2,391 flowers were followed in 2001. Inflorescence size varied among trees and was larger in the second year of study (Table 1). Both inflorescence size and inflorescence number per reproductive shoot varied significantly between populations.

The flowering phenology was left-skewed in both study years (Fig. 1). The flowering season finished earlier in 2001 than in 2000 due to a period of drought and high temperatures. Rates of flower mortality and fruit set changed markedly throughout the course of the flowering season. Early flowers showed a relatively high survival rate but failed almost completely to set fruits. Fruit set increased in the second half of the flowering season until this trend was overridden by a sharply increasing flower mortality (Fig. 1). Desiccation and herbivory were the most important mortality factors in both years (Table 2). Herbivory was highest during the early and mid flowering season, while desiccation prevailed at its end and killed most late flowers before anthesis (Fig. 1). The relative importance of different mortality factors did not vary significantly between the

Table 1 Sources of variation in the number and size of inflorescences monitored over 2 years on 15 Frangula alnus trees

\begin{tabular}{|c|c|c|c|c|c|c|c|c|}
\hline & \multicolumn{4}{|c|}{ Inflorescence number } & \multicolumn{4}{|c|}{ Inflorescence size } \\
\hline & $\mathrm{df}$ & SS & $\mathrm{F}$ & $\mathrm{P}$ & $\mathrm{df}$ & SS & $\mathrm{F}$ & $\mathrm{P}$ \\
\hline Population & 1 & 14.6 & 14.6 & ** & 1 & 39.7 & 39.7 & ** \\
\hline $\begin{array}{l}\text { Tree } \\
\text { (population) }\end{array}$ & 13 & 16.6 & 1.3 & NS & 13 & 60.5 & 4.7 & ** \\
\hline $\begin{array}{l}\text { Year } \\
\text { (tree population) }\end{array}$ & 15 & 2.7 & 0.2 & NS & 13 & 26.4 & 2.0 & $*$ \\
\hline Error & 120 & 24.7 & & & 849 & 730 & & \\
\hline
\end{tabular}

NS Not significant

${ }^{*} \mathrm{P}<0.05 ;{ }^{* *} \mathrm{P}<0.001$ 


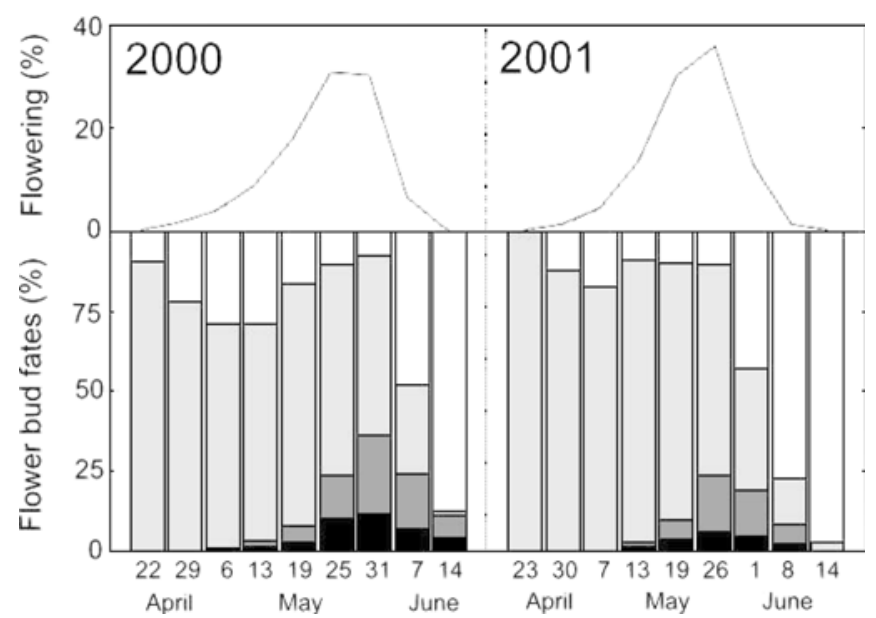

Fig. 1 Frangula alnus flowering phenology (above) and individual bud fates (below) throughout the seasons 2000 and 2001. Phenology data are shown as the percentage of the total number of flowers that opened at a given census date; bud fates refer to the development stage reached by each flower bud that either opened or died at the respective census date. Columns represent buds killed before anthesis (white), open flowers (light grey), flowers initiating fruit (dark grey) and flowers producing mature fruits (black)

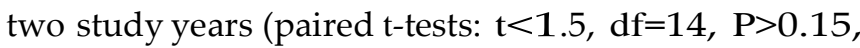
for all factors).

The key-stage analysis indicated that the open flower stage experienced the highest mortality rates, followed by the bud stage (Fig. 2, Table 3). Both stages experienced a markedly higher mortality in 2001 than in 2000, which resulted in a significantly depressed overall seed output (Table 3). Accordingly, initial fruit set reached $27 \pm 18 \%$ in 2000 but only $13 \pm 8 \%$ in 2001 , while final fruit set achieved $9 \pm 6 \%$ in 2000 versus $5 \pm 5 \%$ in 2001 . These differences were statistically significant (paired t-test; initial fruit set: $\mathrm{t}=4.6, \mathrm{df}=14$, $\mathrm{P}<0.001$; final fruit set: $\mathrm{t}=2.2, \mathrm{df}=14, \mathrm{P}=0.04$ ) Both initial and final fruit set varied markedly between individuals $(\mathrm{CV}=18-26 \%$ in both years). Neither stage-specific mortalities nor initial or final fruit set differed between populations (t-test: $\mathrm{df}=31, \mathrm{P}>0.10$ for all comparisons).

The weighted ANCOVA conducted to assess density-dependence of initial and final fruit set revealed significant effects of both tree identity and the size of

Table 2 Causes of flower bud mortality experienced in 2000 and 2001

\begin{tabular}{lll}
\hline Mortality factor & 2000 & 2001 \\
\hline Intrinsic factors & $0.12 \pm 0.16$ & $0.09 \pm 0.10$ \\
Herbivory & $0.35 \pm 0.23$ & $0.37 \pm 0.20$ \\
Desiccation & $0.46 \pm 0.28$ & $0.49 \pm 0.21$ \\
Unknown & $0.07 \pm 0.09$ & $0.05 \pm 0.04$ \\
\hline
\end{tabular}

Data indicate the relative contribution of each factor to total bud mortality (mean $\pm 1 \mathrm{SD}$ ). No significant differences were observed between the two study years (see Results)

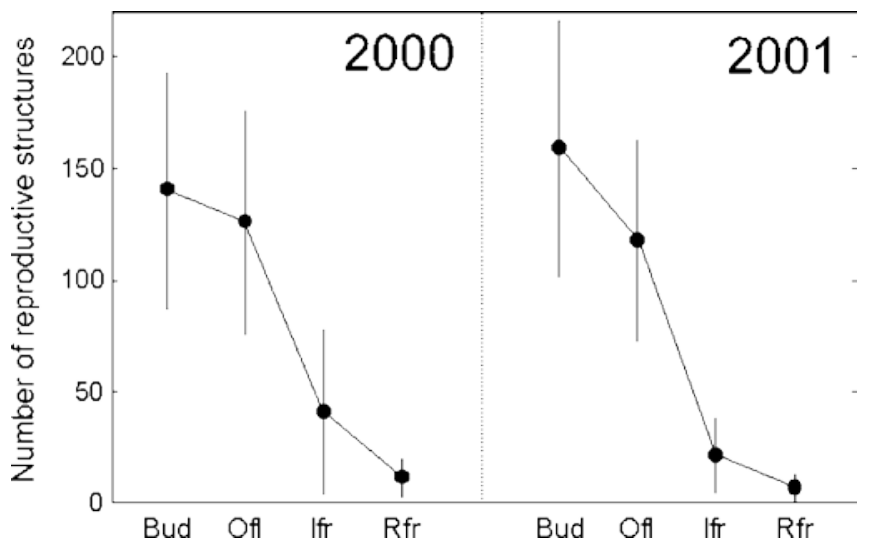

Fig. 2 Number of recorded reproductive structures alive through sequential development stages. Points represent mean values $( \pm 1$ SD) of 15 trees monitored in 2000 and 2001. The considered stages are bud (Bud), open flower (Ofl), initiated fruit (Ifr) and ripe fruit (Rfr). See Table 2 for a statistical comparison of mortalities between the two study years

reproductive structures (inflorescences or infructescences) (Table 4). All regression slopes differed from 1 at $\mathrm{P}<0.0001$ (detailed test results not shown). A marked negative density-dependence of fruit initiation was observed in 2001 (slope $=-0.67$ ), whereas relationships were weak in $2000(-0.05)$. In contrast, density effects on fruit development were clear but only moderately negative in $2000(+0.77)$ and even slightly positive (+1.07) in 2001 .

\section{Pollinator guild and behaviour}

Trees were visited by a diverse array of insects comprising the orders Hymenoptera (55\%), Diptera (23\%), Coleoptera $(20 \%)$ and Lepidoptera $(2 \%, n=815$ visits; see Fig. 3). The rate of pollinator visits increased markedly throughout the flowering season, such that late flowers received five times as many visits per hour as early flowers (Fig. 3).

\section{Pollen addition}

The addition of outcross pollen increased the initial fruit set in all considered trees and doubled mean initial fruit set from $28 \%$ in control flowers to $60 \%$ in treated flowers; final fruit set was $12 \%$ in control and $32 \%$ in treated flowers. Both differences were significant (Wilcoxon test: $\mathrm{Z}=2.8$, $\mathrm{df}=9, \mathrm{P}=0.005$, respectively). The small number of ripe fruits obtained from control flowers made it necessary to pool fruit trait data within trees and to compare tree means for each treatment with paired t-tests. Fruits from the pollen addition treatment were larger than control fruits $(\mathrm{t}=2.5, \mathrm{df}=6, \mathrm{P}=0.05)$ and their filled seeds were heavier $(\mathrm{t}=-3.1, \mathrm{df}=6, \mathrm{P}=0.02)$. Other traits did not differ significantly. 
Table 3 Results of paired t-tests on bud mortality rates during different reproductive stages in 2000 versus 2001

\begin{tabular}{llllcc}
\hline Stage & Submortality & 2000 & 2001 & $\mathrm{t}$ & $\mathrm{df}$ \\
\hline Bud & $\mathrm{k}_{1}$ & $0.05 \pm 0.03(0.04)$ & $0.13 \pm 0.05(0.09)$ & -5.8 & 14 \\
Open flower & $\mathrm{k}_{2}$ & $0.67 \pm 0.37(0.55)$ & $0.84 \pm 0.34(0.57)$ & -3.1 & 14 \\
Unripe fruit & $\mathrm{k}_{3}$ & $0.49 \pm 0.23(0.41)$ & $0.50 \pm 0.28(0.34)$ & 0.3 & 14 \\
Total & $\mathrm{K}$ & $1.21 \pm 0.41(1.00)$ & $1.48 \pm 0.51(1.00)$ & -2.4 & $\mathrm{NS}$ \\
\hline
\end{tabular}

Stage-specific mortalities are given as k-values (mean $\pm 1 \mathrm{SD}$; in parenthesis is the relative contribution of each submortality to the total mortality) according to Yamamura (1999)

NS Not significant

${ }^{*} \mathrm{P}<0.05 ;{ }^{* *} \mathrm{P}<0.01 ;{ }^{* * *} \mathrm{P}<0.001$

Table 4 Results of weighted ANCOVA assessing density-dependence of fruit initiation and development

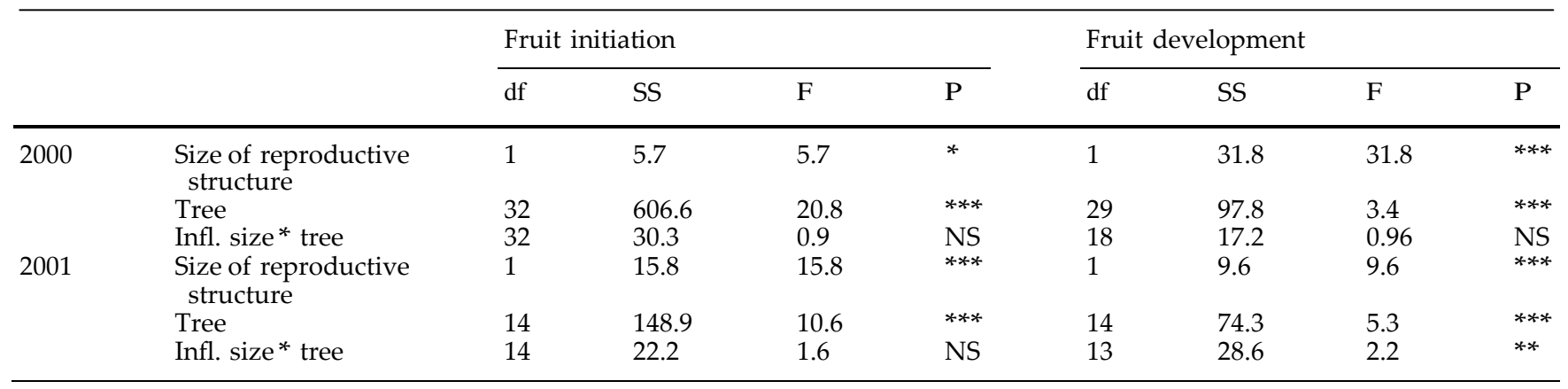

NS Not significant

${ }^{*} \mathrm{P}<0.05 ;{ }^{* *} \mathrm{P}<0.01 ;{ }^{* * *} \mathrm{P}<0.001$

Leaf removal

Leaf clipping increased both initial and final fruit set of the $100 \%$ removal treatment (Fig. 4 , see Table 5 for statistical comparisons). Seed number and seed mass per fruit did not differ significantly between treatments. In contrast, filled seeds from fruits of the $100 \%$ leaf removal treatment were heavier than those resulting from the other two treatments $(100 \%: 2.12 \pm 0.78 ; 50 \%$ : $1.56 \pm 0.62 ; 0 \%$ : $1.65 \pm 0.67)$. Moreover these fruits were smaller, which resulted in a higher seed:pulp ratio.
Effects of phenology

The peak and late flowering treatments achieved a higher initial fruit set than early flowering shoots, while the control treatment took an intermediate position (Fig. 5; see also Table 5). However, final fruit set was by far the highest in the control treatment and almost double that of other treatments. Filled seeds of the late flowering treatment were heavier than those of the early treatment, whereas other fruit traits did not differ significantly (Table 5).
Fig. 3 Pollinator abundance throughout the flowering periods 2000 and 2001. The lower graph shows the absolute number of recorded visits by different taxa; the upper graph indicates the overall number of visits per open flower and hour (mean \pm 1 SE)

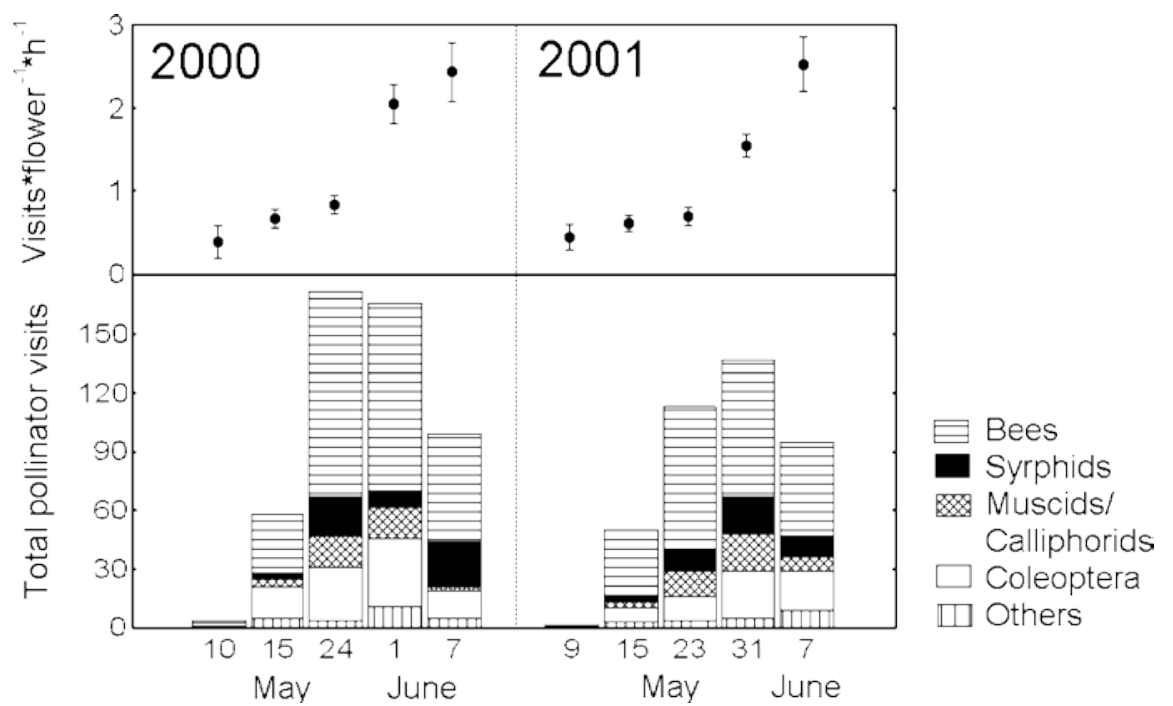




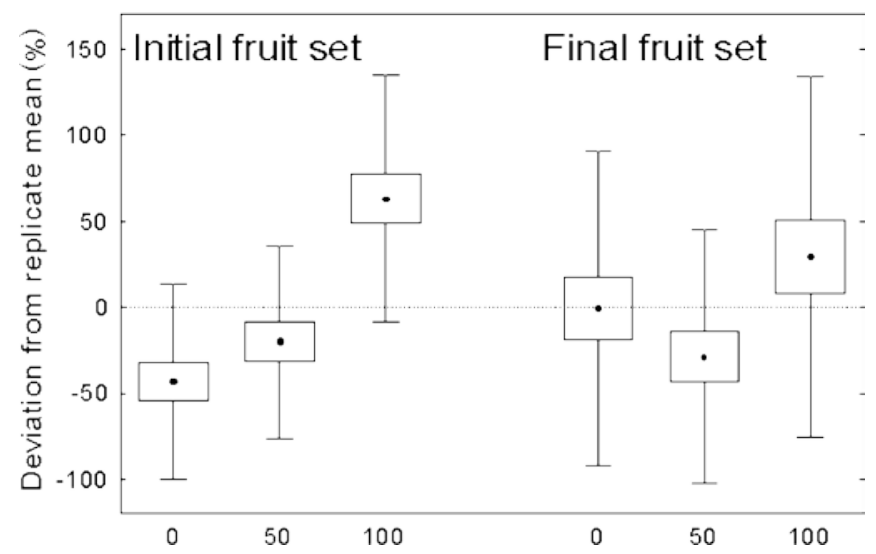

Fig. 4 Initial and final fruit set during the leaf removal experiment; data are shown as relative deviations from the mean fruit set of each replicate to control for the extense variation between replicates. Treatments are 0 (no leaves clipped), 50 (every second leaf clipped), and 100 (all leaves clipped)

\section{Fruit set variation among trees}

Results of the multiple regressions are summarized in Table 6. Initial fruit set was improved in trees with a

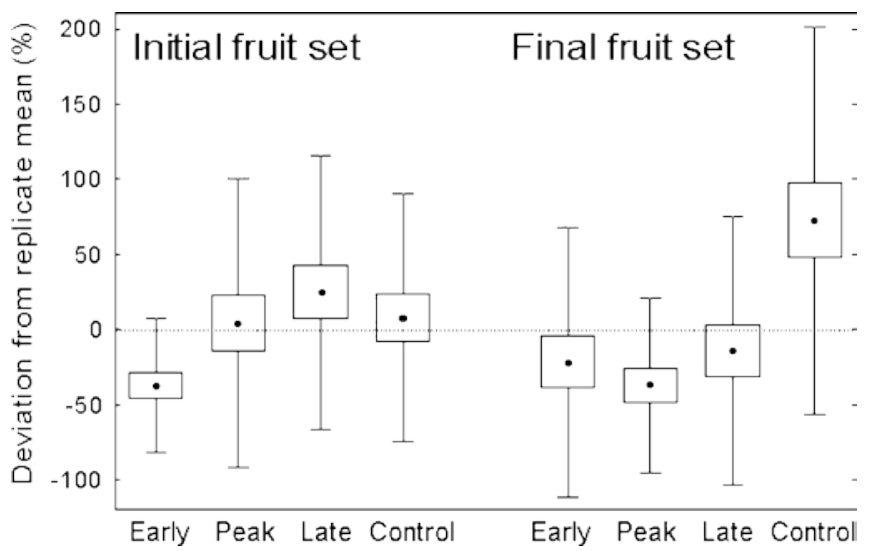

Fig. 5 Initial and final fruit set during the phenology manipulation experiment; data are shown as deviations from the mean fruit set of each replicate to control for the extense variation between replicates. Treatments are early (latest $50 \%$ of flowers clipped just after anthesis), peak (earliest and latest 25\% clipped), late (earliest $50 \%$ clipped), and control (every second flower clipped)

large flower display and at sites with high diffuse radiation (ISF). Final fruit set was highest in late flowering trees that contained many flowers.

Table 5 Statistical comparisons of fruit set and traits of the fruits produced within the leaf removal and the phenological experiment

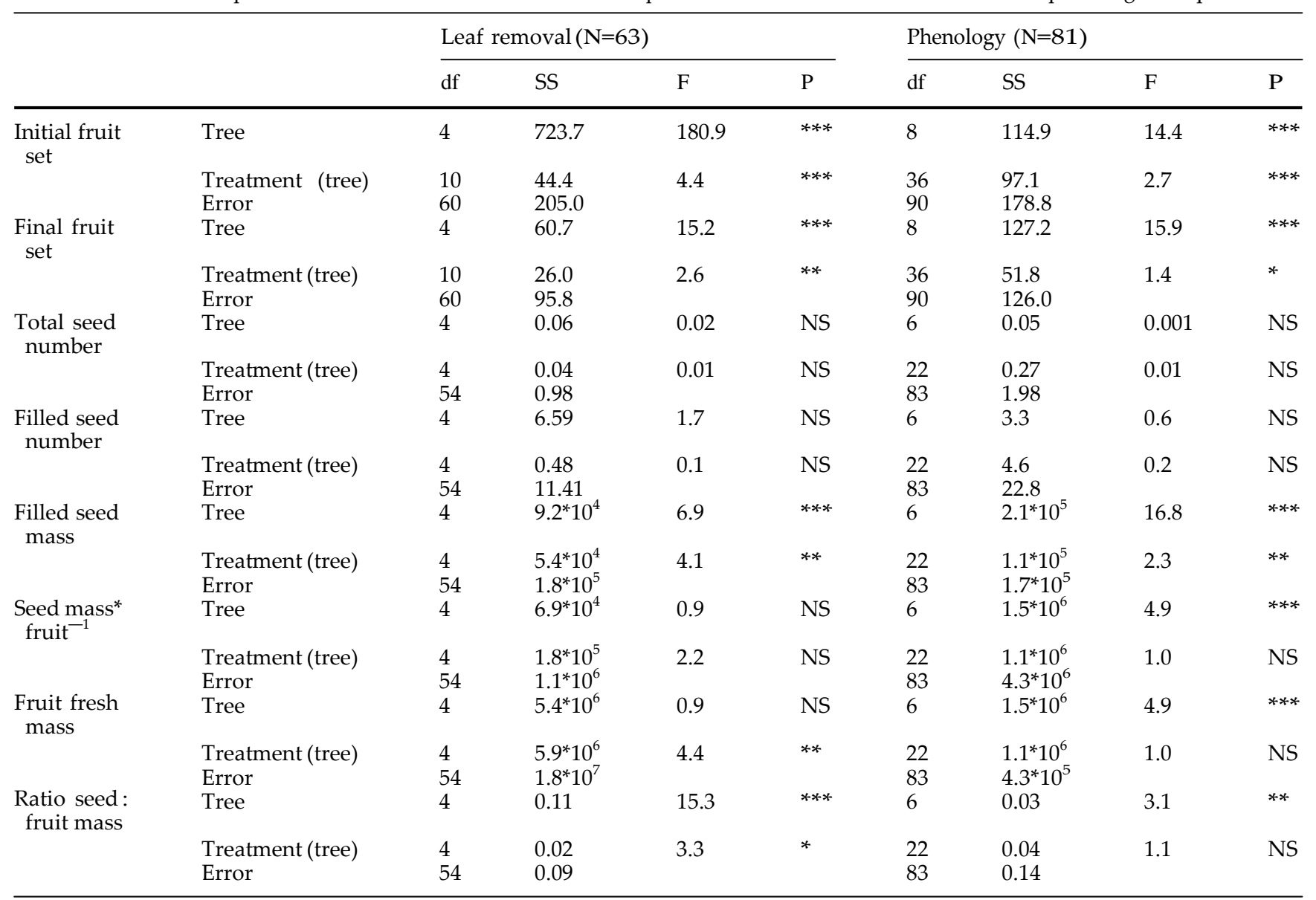

NS Not significant

${ }^{*} \mathrm{P}<0.05 ;{ }^{* *} \mathrm{P}<0.01 ;{ }^{* * * \mathrm{P}<0.001}$ 
Table 6 Multiple regression models for initial and final fruit set of 33 trees monitored in 2000

\begin{tabular}{llllllll}
\hline $\begin{array}{l}\text { Dependent } \\
\text { variable }\end{array}$ & Adj. $\mathrm{R}^{2}$ & $\mathrm{~F}$ & $\mathrm{P}$ & $\begin{array}{l}\text { Significant } \\
\text { predictors }\end{array}$ & $\mathrm{b}$ & $\mathrm{t}$ & $\mathrm{P}$ \\
\hline $\begin{array}{c}\text { Initial fruit } \\
\text { set }\end{array}$ & 0.35 & 3.5 & $*$ & $\begin{array}{l}\text { Total flower } \\
\text { number }\end{array}$ & 0.40 & 2.6 & $*$ \\
Final fruit \\
set
\end{tabular}

Significant predictors are given with their standardized regression coefficients and corresponding statistics

${ }^{*} \mathrm{P}<0.05$

\section{Discussion}

Principal constraints on seed production

The major ovule losses occurred at the open flower stage, while bud and fruit mortality contributed less to the reduction of the reproductive output. In other words, most flowers reached anthesis but failed to set fruit. Broad observational and experimental evidence indicated that low availability of cross pollen is the principal constraint for seed production in these populations. For instance, fruit set increased parallel to the pollinator visitation rate through the flowering period, while the hand cross pollinations improved fruit initiation in all experimental trees and doubled the reproductive output even at the moment of highest natural fruit set. This difference might even underestimate the real pollen limitation, because the flowers'small size, morphology and short period of stigma receptivity render reliable hand pollinations very difficult (A. Hampe, personal observation; see also Medan 1994). Curiously, the experimental removal of leaves likewise strongly increased fruit initiation, probably because the conspicious "stripped" inflorescences attracted pollinators that approached the tree and thus received greater amounts of cross pollen (see also Herrera 1997). The limitation of cross pollen appears to affect entire trees, since fruit initiation of individuals was related to the size of the flower display. This may be expected when cross pollen availability is limited (pollinator attraction hypothesis, Willson and Price 1977). The observed positive effect of the ISF on fruit initiation (but not development) may likewise be interpreted as a sign that high levels of diffuse radiation improve flower visibility and hence pollination success. The reported pollen limitation of seed set contrasts with observations of high pollinator abundance (as predicted for southern range margin populations) and suggests that the studied F. alnus populations are experiencing extensive geitonogamy (de Jong et al. 1993; Wilcock and Neiland 2002).

The analysis of density-dependence showed that the pollination regime may even override local resource limitation during fruit development. Whereas in 2000 inflorescence size scarcely affected fruit initiation and generated a clear but moderate negative effect on fruit development, in 2001 a marked negative densitydependence of fruit initiation resulted even in a slightly positive effect of infructescence (not inflorescence) size on fruit development. This rather unexpected result may arise when the ability of infructescences to acquire recourses from other plant parts outweighs effects of local competition between their fruits. This appears most probable when fruit initiation is so low that many inflorescences do not arrive to set any fruit, as in the present case. The results of the leaf removal experiments further underline the importance of pollination compared to resource limitation. Fruit initiation was so improved in shoots with all their leaves clipped that, despite their increased levels of fruit abortion, these produced slightly more ripe fruits and significantly heavier filled seeds than other shoots. Likewise, the presumably most favourable pollination regimes generated in the other two experiments (pollen addition and phenology manipulation) resulted in the production of heavier seeds. Possible reasons might be that these treatments experienced reduced inbreeding or that elevated competition between pollen grains on the stigma resulted in preferential fecundation by high-quality pollen.

Once successful pollination had taken place, some resource limitation was, however, apparent. In addition to the above-mentioned negative density-dependence of fruit development detected in 2000, the phenological experiment revealed that fruit development was markedly improved in the treatment which provided the longest time intervals between the anthesis of subsequent flowers (i.e., the control treatment). Hence, competition appeared to affect particularly those fruits that were sired about the same time. Many fruits were shed during the water-consuming process of fruit enlargement, so water availability might limit the number of fruits within an inflorescence or shoot that can enter this stage simultaneously. The character of fruits produced within the leaf removal experiment permits some further inferences about resource limitations in F. alnus. Seed development is apparently not affected by leaf removal, as the total seed mass per fruit did not differ among experimental treatments and filled seeds were even heavier (as described above). In contrast, fruits from leafless shoots had a markedly reduced pulp, indicating that these shoots do possibly not achieve a sufficiently high negative water potential to obtain the water that fruits require for complete enlargement.

Within- and between-season variation of seed production

The start of the flowering period in the study populations is most probably triggered by temperature cues (Rotzer and Chmielewski 2001), and in both years it took place about the same date. In contrast, the end of 
the flowering season is determined by the onset of summer drought, whose timing may vary considerably between years according to the amount of winter precipitation and the meteorological conditions in early summer (SinambA Difusion 1998). On the other hand, successful fruit initiation is mostly confined to a relatively short time of peak pollinator abundance before drought kills the latest flowers. Annual reproduction thus depends largely on favourable meteorological conditions during this period. While in 2000 the weather was relatively suitable, the critical period of the 2001 flowering season coincided with a period of dry, warm and windy weather (A. Hampe, personal observation). The result was an earlier end of the 2001 flowering period and a roughly $50 \%$ decrease of the seed output compared to the previous year. Taking into account that 2001 was far from being a particularly unfavourable year (cf. SinambA Difusion 1998), this range seems comparable to the great between-year variation of fruit production commonly reported from plant populations growing at high-latitude range margins (e.g. Despland and Houle 1997; Houle and Filion 1993; Tremblay et al. 2002). However, additional study years would be desirable to confirm this notion (see Hampe 2004 for longer-term data on seed rain and seedling recruitment).

Reproductive biology and population viability at the southern range margin

Contrary to predictions, pollen limitation is the principal constraint for the reproductive potential of the studied F. alnus populations. Pollination regimes are usually influenced by plant population characteristics such as size, density, spatial distribution and isolation, and in self-incompatible species like F. alnus also by the genetic population structure (Wilcock and Neiland 2002). Present-day populations of the subspecies F. a. baetica are typically small (often $<100$ trees), isolated, sparse and progressively declining (Anonymous 2000, Hampe and Arroyo 2002). The observed pronounced concentration of the population seed output to few large trees (Hampe and Arroyo 2002), reinforced by the linear distribution of plants along riverbeds (Cunningham 2000) and combined with an extremely efficient population-wide dispersal of produced seeds (Hampe 2004) may ultimately contribute to homogenize the genetic structure of populations and reduce their diversity, as few plants manage to spread out their offspring across populations and dominate the regeneration whereas most others scarcely participate in it.

South Iberian F. alnus populations are very old and stable relicts that most probably date back to the Tertiary (Hampe et al. 2003). Throughout recent decades, however, they have disappeared from important parts of the historical range. Spring rainfall in the region has decreased more than $30 \%$ through the last century, while mean spring temperatures have increased significantly during the last 20 years (Garcia
Barron 2000). In contrast, winter precipitation and temperatures have remained largely constant. An earlier onset of summer drought could therefore merely be buffered by earlier budburst and flowering, and a progressive shortening of the flowering season-in particular its most important part-would be the logical consequence. It therefore seems probable that current regional climate trends are progressively reducing the reproductive potential of South Iberian F. alnus relict populations and are contributing to rendering the region a "trailing edge" of the species' poleward shifting range.

Acknowledgements Many thanks to Felipe Oliveros for the permission to work in the "Los Alcornocales" Natural Park and logistical support in the area. Begona Garrido helped with field work, Kjell Bolmgren inspired the experimental studies, while Pauline Garnier-Gere and especially Pedro Jordano kindly helped with the statistics, and comments from Pedro Jordano, Juan Arroyo and two anonymous referees considerably improved earlier versions of this manuscript. The study received support from the MCyT research grants PB98-1144 and BOS2002-01162, the CICYT-FEDER grant 1FD97-0743-C03-03 and a research contract with the public company GIASA (Sevilla). It is a contribution to the Andalusian research network REDBOME. All conducted experiments complied with valid legislation.

\section{References}

Anonymous (2000) Lista Roja de la Flora Vascular Espanola (valoracion segun categorias UICN). Conserv Vegetal 6 (extra):11-38

Bale JS, Masters GJ, Hodkinson ID, Awmack C, Bezemer TM, Brown VK, Butterfield J, Buse A, Coulson JC, Farrar J, Good JEG, Harrington R, Hartley S, Jones TH, Lindroth RL, Press MC, Symrnioudis I, Watt AD, Whittaker JB (2002) Herbivory in global climate change research: direct effects of rising temperature on insect herbivores. Global Change Biol 8:1-16

Bond WJ (1995) Effects of global change on plant-animal synchrony: implications for pollination and seed dispersal in Mediterranean habitats. In: Moreno JM, Oechel WC (eds) Global change and Mediterranean-type ecosystems. Springer, Berlin Heidelberg New York, pp 181-202

Castro J, Zamora R, Hodar JA, Gomez JM (2004) Seedling establishment of a boreal tree species (Pinus sylvestris) at its southernmost distribution limit: consequences of being in a marginal Mediterranean habitat. J Ecol 92:266-277

Crawley MJ (2002) Statistical computing: an introduction to data analysis using S-Plus. Wiley, Chichester

Cunningham SA (2000) Depressed pollination in habitat fragments causes low fruit set. Proc R Soc Lond B 267:1149-1152

Delta-T Devices (1998) HemiView canopy analysis software Version 2.1. Delta-T Devices Ltd., Cambridge

Despland E, Houle G (1997) Climate influences on growth and reproduction of Pinus banksiana (Pinaceae) at the limit of the species distribution in eastern North America. Am J Bot 84:928-937

Dorken ME, Eckert CG (2001) Severely reduced sexual reproduction in northern populations of a clonal plant, Decodon verticillatus (Lythraceae). J Ecol 89:339-350

Garcia Barron L (2000) Analisis de series termopluviometricas para la elaboracion de modelos climaticos en el suroeste de Espana. PhD thesis, Sevilla University

Garcia D, Zamora R, Hodar JA, Gomez JM (1999) Age structure of Juniperus communis L. in the Iberian Peninsula: conservation of remnant populations in Mediterranean mountains. Biol Conserv 87:215-220 
Godwin H (1943) Biological flora of the British Isles: Rhamnaceae. J Ecol 31:66-92

Hampe A (2001) The role of fruit diet within a temperate breeding bird community in southern Spain. Bird Study 48:116-123

Hampe A (2004) Extensive hydrochory uncouples spatiotemporal patterns of seedfall and seedling recruitment in a "bird-dispersed" riparian tree. J Ecol 92:797-807

Hampe A, Arroyo J (2002) Recruitment and regeneration in populations of an endangered South Iberian Tertiary relict tree. Biol Conserv 107:263-271

Hampe A, Bairlein F (2000) Modified dispersal-related traits in disjunct populations of bird-dispersed Frangula alnus (Rhamnaceae) - a result of its Quaternary distribution shifts? Ecography 23:603-613

Hampe A, Arroyo J, Jordano P, Petit RJ (2003) Rangewide phylogeography of a bird-dispersed Eurasian shrub: contrasting Mediterranean and temperate glacial refugia. Mol Ecol 12:34153426

Herrera J (1997) The role of coloured accessory bracts in the reproductive biology of Lavandula stoechas. Ecology 78:494-504

Houle G, Filion L (1993) Interannual variations in the seed production of Pinus banksiana at the limit of the species distribution in northern Quebec, Canada. Am J Bot 80:1242-1250

IPCC (2001) Climate change 2001: the scientific basis. Cambridge University Press, Cambridge

de Jong TJ, Waser NM, Klinkhamer PGL (1993) Geitonogamy: the neglected side of selfing. Trends Ecol Evol 9:307-344

Kevan BG, Baker HG (1983) Insects as flower visitors and pollinators. Annu Rev Entomol 28:407-453

Lawton JH (1993) Range, population abundance and conservation. Trends Ecol Evol 8:409-413

Medan D (1994) Reproductive biology of Frangula alnus Miller in Southern Spain. Plant Syst Evol 193:173-186

Olesen JM, Jordano P (2002) Geographic patterns in plant-pollinator mutualistic networks. Ecology 83:2416-2424

Parmesan C, Yohe G. (2003) A globally coherent fingerprint of climate change impacts across natural systems. Nature 421:37-42
Philippi TE (1993) Multiple regression analysis: herbivory. In: Scheiner SM, Gurevitch J (eds) Design and analysis of ecological experiments. Chapman and Hall, New York, pp 183-210

Pigott CD (1992) Are the distributions of species determined by failure to set seed? In: Marshall C, Grace J (eds) Fruit and seed production: aspects of development, environmental physiology and ecology. Cambridge University Press, Cambridge, pp 203216

Pigott CD, Huntley JP (1981) Factors controling the distribution of Tilia cordata at the northern limits of its geographic range. III. Nature and causes of seed sterility. New Phytol 87:817-839

Pigott CD, Pigott S (1993) Water as a determinant of the distribution of trees at the boundary of the Mediterranean zone. J Ecol 81:557-566

R Development Core Team (2004) R: a language and environment for statistical computing. http://www.R-project.org

Rotzer T, Chmielewski FM (2001) Phenological maps of Europe. Clim Res 18:249-257

SinambA Difusion (1998) La Informacion Ambiental de Andalucıa. Consejerıa de Medio Ambiente, Junta de Andalucia, Sevilla

StatSoft (2001) STATISTICA (data analysis software system), Version 6. http://www.statsoft.com

Tremblay MF, Bergeron Y, Lalonde D, Mauffette Y (2002) The potential effects of sexual reproduction and seedling recruitment on the maintenance of red maple (Acer rubrum) populations at the northern limit of the species range. J Biogeogr 29:365-373

Wagner J, Mitterhofer E (1998) Phenology, seed development, and reproductive success of an alpine population of Gentianella germanica in climatically varying years. Bot Acta 111:159-166

Wilcock C, Neiland R (2002) Pollination failure in plants: why it happens and when it matters. Trends Plant Sci 7:270-277

Willson MF, Price PW (1977) The evolution of inflorescence size in Asclepias (Asclepiadaceae). Evolution 31:495-511

Woodward FI (1987) Climate and plant distribution. Cambridge University Press, Cambridge

Yamamura K (1999) Key-factor/key-stage analysis for life table data. Ecology 80:533-537 